\title{
High arachidonic acid levels in the cord blood of infants of mothers on vegetarian diets
}

\author{
BY J. P. STAMMERS AND D. HULL \\ Department of Child Health, University Hospital, Queen's Medical Centre, \\ Nottingham NG7 $2 U H$ \\ AND R. ABRAHAM \\ Northwick Park Hospital, Watford Road, Harrow, Middlesex HAl 3 UJ \\ AND I. R. MCFADYEN \\ Department of Perinatal Medicine, MRC Clinical Research Centre, Harrow, \\ Middlesex $\mathrm{HAl} 3 \mathrm{UJ}$
}

(Received 26 November 1987 - Accepted 24 August 1988)

\begin{abstract}
1. Maternal and umbilical cord plasma samples were collected from forty-seven Asian women, twenty-eight lifelong vegetarians and seventeen non-vegetarians, during delivery of their babies. The concentrations and fatty acid profiles of the plasma free fatty acid and triacylglycerol fractions were determined.

2. There were no significant differences between the levels of free fatty acid and triacylglycerol in either maternal or cord plasma from vegetarian compared with non-vegetarian Asian women. The fatty acid profiles of the lipid fractions in the two groups were similar. Total plasma free fatty acid levels in the maternal circulation correlated with umbilical cord levels.

3. The levels of linoleic acid in the maternal plasma free fatty acid fraction of the Asian women were much higher than previous reports on mixed populations of European women. In the Asian women arachidonic acid concentrations in both maternal and umbilical circulations were over four times higher than those reported for women unselected for race and diet.
\end{abstract}

Investigations in animals have shown that maternal plasma free fatty acids are an important source of fetal lipids in some mammals, e.g. rabbit (Elphick \& Hull, 1977 a), whilst not in others, e.g. sheep (Elphick et al. 1979). In some species fatty acids can reach the fetus from both maternal plasma free fatty acid and triacylglycerol, e.g. rabbit (Elphick \& Hull, $1977 a, b$; Elphick et al. 1978; Stammers et al. 1983) and guinea-pig (Thomas \& Lowy, 1982). In others, maternal plasma phospholipid is thought to be important for the supply of certain long-chain polyunsaturated fatty acids to the fetus, e.g. cat (Elphick \& Hull, 1984).

A number of studies in human beings have noted a small but significant umbilical vein-artery difference in free fatty acids (Sabata et al. 1968; Tobin et al. 1969; Sabata \& Wolf, 1970; Persson \& Tunell, 1971; Sheath et al. 1972; Elphick et al. 1976) and some report a positive correlation between maternal venous and umbilical cord blood free fatty acid concentrations (Whalley et al. 1966; Sabata et al. 1968; Sabata \& Wolf, 1970; Elphick et al. 1976). The fatty acid composition of plasma lipids in mixed umbilical cord blood samples has been examined in several investigations (Chen et al. 1965; Robertson et al. 1968; King et al. 1971; Fosbrooke \& Wharton, 1973; Friedman et al. 1978). In one study separate umbilical cord artery and vein blood samples were obtained during elective Caesarean section and significant umbilical vein-artery differences were found for a number of individual free fatty acids (Hendrickse et al. 1985). The evidence, therefore, suggests that free fatty acids do cross the human placenta. In man the extent to which they do so throughout pregnancy is not known. The contribution made by maternal circulating 
Table 1. Clinical details of pregnant vegetarian and non-vegetarian Asian women participating in the study

\begin{tabular}{|c|c|c|c|c|c|}
\hline $\begin{array}{c}\text { Subject } \\
\text { no. }\end{array}$ & $\begin{array}{c}\text { Age } \\
\text { (years) }\end{array}$ & Parity & $\begin{array}{c}\text { Gestation } \\
\text { (weeks) }\end{array}$ & $\begin{array}{l}\text { Type of } \\
\text { delivery }\end{array}$ & $\begin{array}{c}\text { Birth } \\
\text { wt (kg) }\end{array}$ \\
\hline \multicolumn{6}{|c|}{ Non-vegetarian } \\
\hline 1 & 35 & 1 & 39 & $\mathrm{C} / \mathrm{S}$ & $3 \cdot 60$ \\
\hline 2 & 23 & 1 & 40 & Normal & $3 \cdot 26$ \\
\hline 3 & 27 & 1 & 33 & Normal & 2.07 \\
\hline 4 & 30 & 1 & 38 & Normal & $2 \cdot 88$ \\
\hline 5 & 24 & 2 & 39 & Normal & $3 \cdot 72$ \\
\hline 6 & 22 & 0 & 39 & Normal & 3.02 \\
\hline 7 & 31 & 0 & 40 & Normal & $2 \cdot 97$ \\
\hline 8 & 20 & 0 & 38 & Normal & 2.89 \\
\hline 9 & 31 & 1 & 40 & Normal & 3.04 \\
\hline 10 & 24 & 0 & $?$ & Normal & $3 \cdot 44$ \\
\hline 11 & 25 & 0 & 41 & Normal & $3 \cdot 25$ \\
\hline 12 & 27 & 0 & 39 & Normal & $2 \cdot 90$ \\
\hline 13 & 25 & 2 & 40 & Normal & 3.04 \\
\hline 14 & 25 & 0 & 40 & Normal & $3 \cdot 12$ \\
\hline 15 & 31 & 4 & 40 & Normal & 3.90 \\
\hline 16 & 25 & 0 & 39 & Normal & $2 \cdot 88$ \\
\hline 17 & 34 & 2 & 39 & $\mathrm{C} / \mathrm{S}$ & $2 \cdot 96$ \\
\hline 18 & 24 & 1 & 41 & Normal & $3 \cdot 30$ \\
\hline 19 & 34 & 4 & 39 & Normal & $3 \cdot 21$ \\
\hline \multicolumn{6}{|l|}{ Vegetarian } \\
\hline 20 & 24 & 1 & 40 & Normal & $3 \cdot 20$ \\
\hline 21 & 23 & 0 & 39 & Forceps & $2 \cdot 72$ \\
\hline 22 & 31 & 0 & 38 & Normal & $2 \cdot 88$ \\
\hline 23 & 22 & 0 & $?$ & Normal & 3.06 \\
\hline 24 & 34 & 1 & 39 & Normal & 3.98 \\
\hline 25 & 21 & 0 & 39 & Normal & $2 \cdot 30$ \\
\hline 26 & 24 & 0 & 39 & Normal & $3 \cdot 40$ \\
\hline 27 & 27 & 0 & 41 & Normal & $3 \cdot 10$ \\
\hline 28 & 33 & 0 & 39 & Normal & 2.82 \\
\hline 29 & 32 & 1 & 40 & Norma! & 2.59 \\
\hline 30 & 24 & 0 & 41 & Normal & $2 \cdot 90$ \\
\hline 31 & 25 & 1 & $?$ & Normal & $3-90$ \\
\hline 32 & 31 & 1 & 39 & Normal & 3.58 \\
\hline 33 & 28 & 1 & 39 & Normal & $3 \cdot 16$ \\
\hline 34 & 25 & 1 & 38 & Normal & $2 \cdot 88$ \\
\hline 35 & 28 & 0 & 37 & Normal & 3.04 \\
\hline 36 & 29 & 1 & 41 & Normal & 3.94 \\
\hline 37 & 29 & 1 & 39 & Normal & $2 \cdot 70$ \\
\hline 38 & 29 & 0 & 40 & Normal & $2 \cdot 89$ \\
\hline 39 & 21 & 0 & 39 & Normal & $2 \cdot 74$ \\
\hline 40 & 31 & 0 & 39 & Normal & $2 \cdot 54$ \\
\hline 41 & 25 & 0 & 40 & Normal & $3 \cdot 36$ \\
\hline 42 & 32 & 1 & 40 & Normal & $3 \cdot 14$ \\
\hline 43 & 24 & 0 & 41 & Normal & $3 \cdot 38$ \\
\hline 44 & 22 & 0 & 39 & Normal & $2 \cdot 78$ \\
\hline 45 & 26 & 1 & 39 & Normal & $3 \cdot 12$ \\
\hline 46 & 21 & 0 & 39 & Normal & $2 \cdot 28$ \\
\hline 47 & 27 & 0 & 39 & Normal & 2.83 \\
\hline
\end{tabular}

C/S, Caesarean. 
triacylglycerol and phospholipid to free fatty acids entering the fetal circulation, or indeed the extent to which the placenta might influence the composition of the fatty acids entering the umbilical circulation is also difficult to determine. One approach would be to examine fetal blood lipids from mothers on different diets. The opportunity was taken to determine lipids in cord blood obtained from Asian mothers, some of whom were strict vegetarians and whose dietary intake had been analysed. A high dietary linoleic acid content appears to lead to high arachidonic acid levels reaching the fetus.

\section{SUBJECTS AND METHODS}

Forty-seven Asian women, twenty-eight life-long vegetarians and nineteen non-vegetarian, were included in the study. The women attended Northwick Park Hospital, Harrow during their pregnancies and for delivery of their babies. Clinical details of the patients are given in Table 1. A dietary recall of food intake was taken for $5 \mathrm{~d}$ before delivery using household measures and food models to quantify the food, which although less reliable than a weighed record was felt to be more suitable for the subjects. The nutrient content of the diet was determined using the values in Paul \& Southgate (1978). Foods for which information was not available were analysed for fatty acid content. Maternal blood samples were taken just before delivery and umbilical cord blood was taken as quickly as possible after delivery of the infant, but before delivery of the placenta. Blood samples were collected into heparinized tubes on ice. The samples were centrifuged to remove cells and the plasma stored at $-20^{\circ}$ until analysis.

The concentration and composition of the free fatty acid fraction were determined using $500 \mu \mathrm{l}$ plasma samples extracted according to Itaya \& Ui (1965). Methyl esters of the extracted fatty acids were prepared and separated by gas-liquid chromatography as described by Elphick \& Hull $(1977 a)$. The concentration and fatty acid composition of the triacylglycerol fraction were measured using $1 \mathrm{ml}$ plasma samples extracted into chloroform-methanol $(2: 1, \mathrm{v} / \mathrm{v})$ (Folch et al. 1957). The extracted lipids were separated using a combination of thin-layer and gas-liquid chromatography as described in detail elsewhere (Elphick \& Lawlor, 1977; Elphick \& Hull, 1977a).

\section{RESULTS}

The mean daily intakes of individual fatty acids for the vegetarian and non-vegetarian Asian women are given in Fig. 1. The levels of the predominant fatty acids of the diet were similar in the vegetarian and non-vegetarian women. Arachidonic and docosahexaenoic acids together formed less than $0.2 \%$ of the total dietary fatty acids of the non-vegetarian women, but were significantly higher than the levels of these fatty acids in the vegetarian diet $(P<0.001$ and $P<0.01$ respectively).

The total fatty acid levels in the plasma free fatty acid and triacylglycerol fractions of maternal and umbilical cord blood are given in Table 2. There were no significant differences in either maternal or umbilical plasma free fatty acid and triacylglycerol concentrations between vegetarian and non-vegetarian women. When total plasma free fatty acid levels in the umbilical circulation were compared with maternal levels, a significant positive correlation emerged (Fig. 2).

The fatty acid composition of the maternal and umbilical cord plasma free fatty acid and triacylglycerol fractions are shown in Fig. 3. Since the plasma lipids of the vegetarian and non-vegetarian women were similar in composition the results are combined. 
(a) Non-vegetarian

(b) Vegetarian

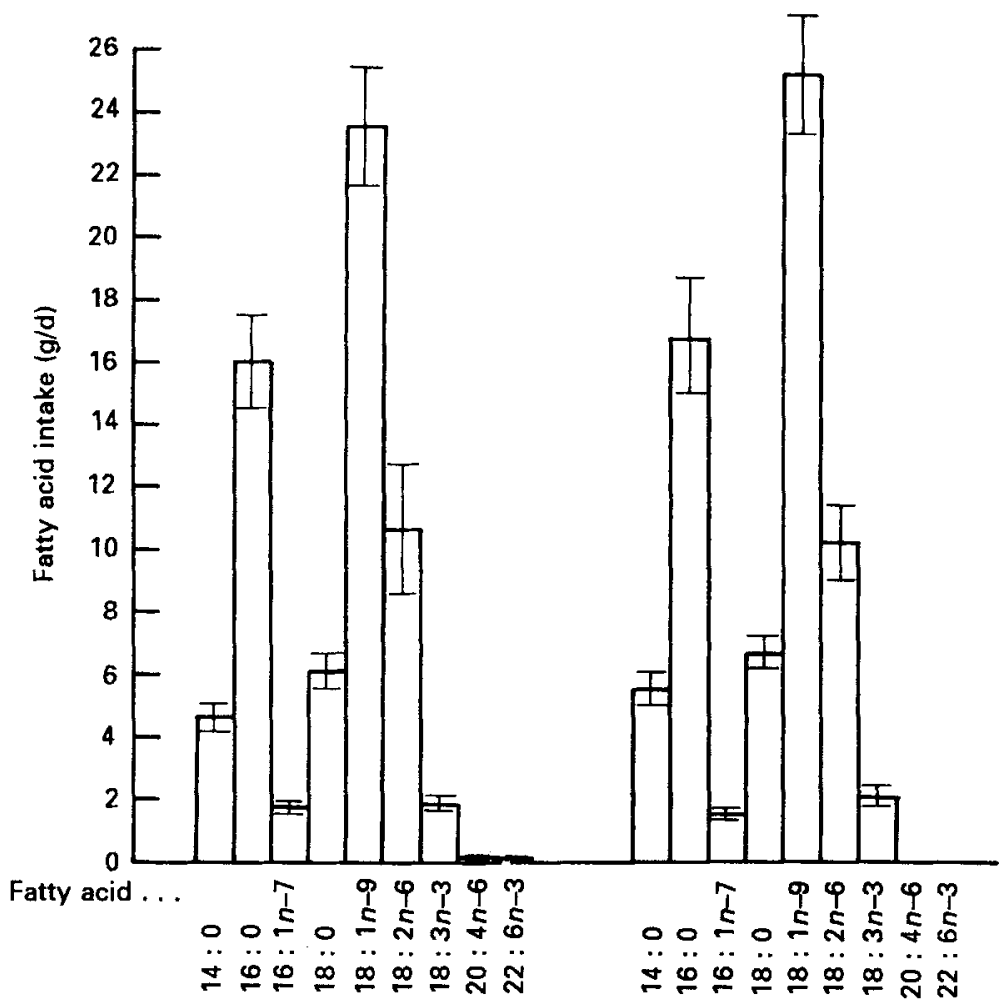

Fig. 1. The daily intake of individual fatty acids of $(a)$ pregnant non-vegetarian Asian women $(n 19)$ and (b) pregnant vegetarian Asian women $(n 28)$. Results are means with their standard errors represented by vertical bars.

Table 2. Concentrations of maternal and umbilical cord plasma lipids in pregnant vegetarian and non-vegetarian Asian women

(Mean values with their standard errors; no. of subjects in parentheses)

\begin{tabular}{|c|c|c|c|c|}
\hline \multirow[b]{2}{*}{ Sample } & \multicolumn{2}{|c|}{ Non-vegetarian (19) } & \multicolumn{2}{|c|}{ Vegetarian (28) } \\
\hline & Mean & SEM & Mean & SEM \\
\hline \multicolumn{5}{|l|}{ Maternal plasma: } \\
\hline $\begin{array}{l}\text { Free fatty acid } \\
(\mathrm{mmol} / \mathrm{l})\end{array}$ & 0.964 & 0.096 & $1 \cdot 110$ & 0.157 \\
\hline $\begin{array}{l}\text { Triacylglycerol } \\
(\mathrm{mmol} / 1)\end{array}$ & 3.860 & 0.475 & $4 \cdot 290$ & 0.445 \\
\hline \multicolumn{5}{|c|}{ Umbilical cord plasma: } \\
\hline $\begin{array}{l}\text { Free fatty acid } \\
(\mathrm{mmol} / \mathrm{l})\end{array}$ & 0.521 & 0.039 & 0.523 & 0.027 \\
\hline $\begin{array}{l}\text { Triacylglycerol } \\
(\mathrm{mmol} / \mathrm{l})\end{array}$ & 0.698 & 0.055 & 0.845 & 0.069 \\
\hline
\end{tabular}




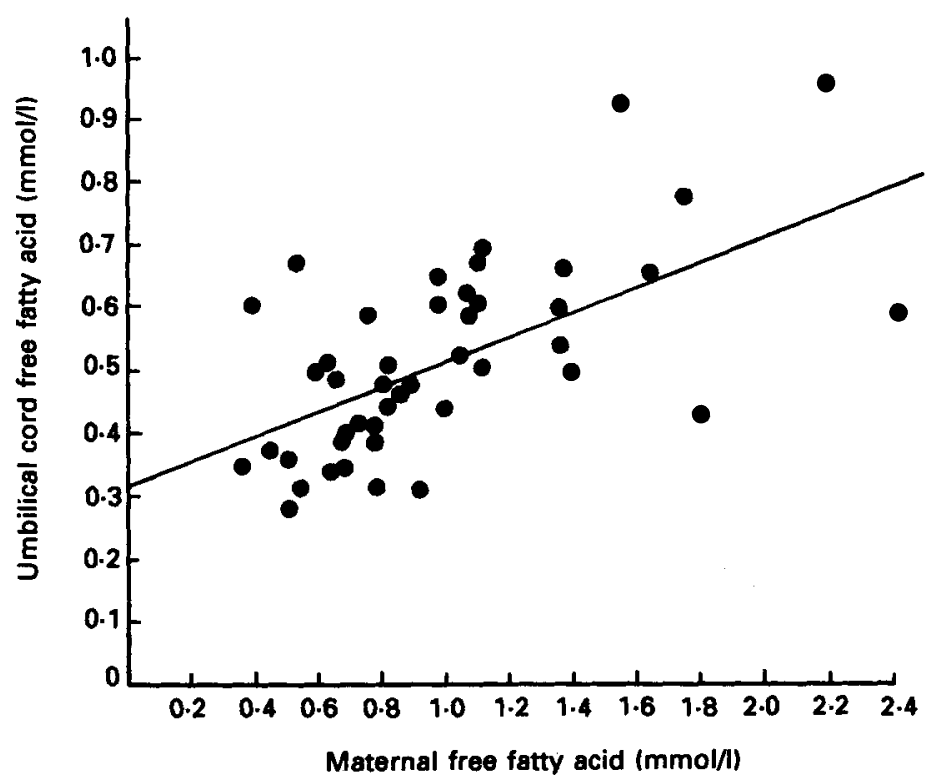

Fig. 2. The relation between maternal and umbilical cord plasma free fatty acid levels of both pregnant vegetarian and non-vegetarian Asian women. The regression line is given by the formula:

$$
y=0.203 x+0.316(P<0.001, r 0.612, n 47) \text {. }
$$

\section{DISCUSSION}

The similarity in the types and content of dietary fatty acids between the vegetarian and non-vegetarian Asian women could be because Gujarati non-vegetarians are in the main vegetarians who include a little meat as a 'side dish' (Abraham, 1983) and the majority of the fat in their diet is of vegetable origin. Long-chain polyunsaturated derivatives of the essential fatty acids are produced through elongation and desaturation in animal tissues and are thus provided in the diet by meat. The levels of these fatty acids in the nonvegetarian diet, though significantly higher than those in the vegetarian diet, were low compared with other fatty acids. The fatty acid compositions of the plasma free fatty acid and triacylglycerol fractions were similar in both groups of Asian women, unlike previous studies where differences in plasma lipid composition have been shown between vegans and omnivores (Sanders et al. 1978). The subjects of this study, however, were middle-class Caucasians and the difference in meat intake between the vegans and omnivores is likely to be much greater than that in our study.

It is recognized that caution is required when interpreting information gathered from umbilical cord blood samples taken following vaginal delivery, when labour has induced high maternal plasma free fatty acid levels and placental blood flow has been interrupted to a varied extent. Some information can be obtained, however. For example, previous studies have demonstrated a direct significant correlation between maternal and umbilical plasma free fatty acid concentrations (Whalley et al. 1966; Sabata et al. 1968; Sabata \& Wolf, 1970). This relation has been confirmed in blood samples taken at elective Caesarean section where interference with placental blood flow would be less and the mother would not have experienced labour (Elphick et al. 1976). The correlation between maternal and umbilical cord plasma free fatty acid concentrations found in both the vegetarian and non- 
(a) Free fatty acid

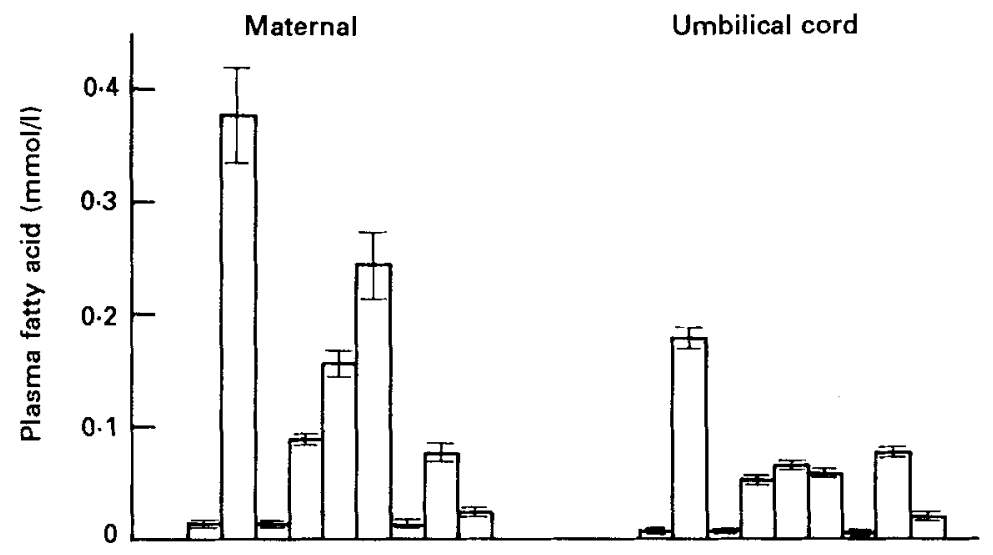

(b) Triacylglycerol

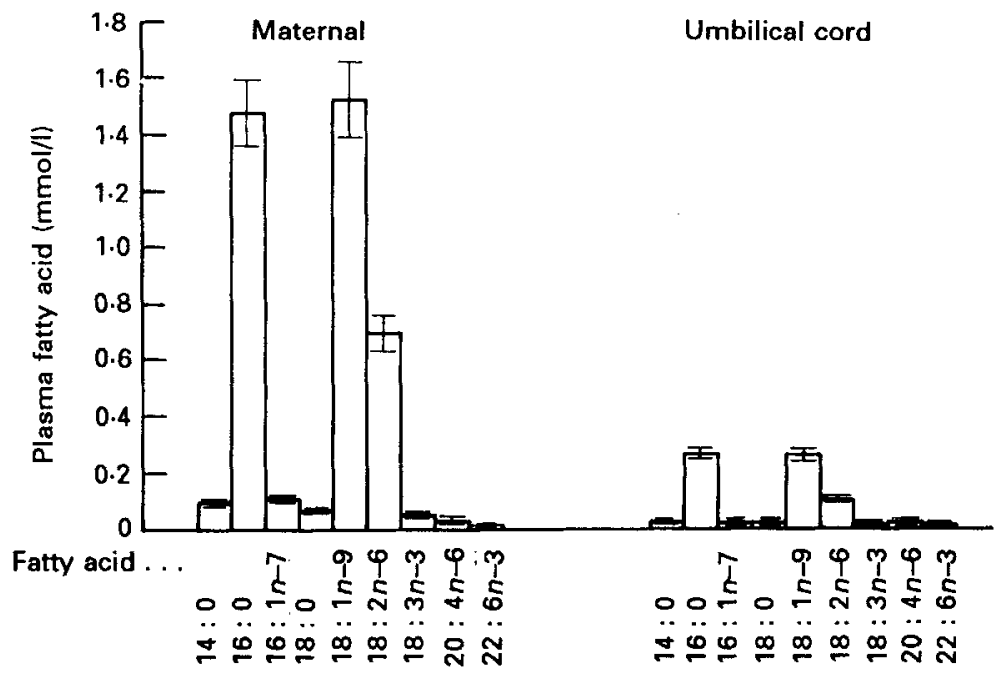

Fig. 3. Plasma concentrations of the individual fatty acids in the free fatty acid and triacylglycerol fractions of maternal and umbilical cord blood of both pregnant vegetarian and non-vegetarian Asian women. Results are means with their standard errors represented by vertical bars.

vegetarian Asians was similar to that found by Elphick et al. (1976) in Caucasians. At normal delivery of term infants linoleic acid has been reported at levels of 8-14 and $14-18 \%$ of the maternal plasma free fatty acid and triacylglycerol fractions respectively. Linoleic acid in the umbilical circulation of these infants formed approximately $10 \%$ of the free fatty acid and triacylglycerol fractions (Chen et al. 1965; Robertson et al. 1968; King et al. 1971; Friedman et al. 1978). The diets and race of the women used in these studies were not stated, but presumably represented an unselected mixture of the country of origin. Whilst the proportion of linoleic acid in the maternal plasma triacylglycerol fraction of our Asian women was similar to that in the earlier studies, the linoleic acid of the maternal free fatty acid fraction formed $20 \%$, which was much higher than in previous reports. The storage of plasma samples at $-20^{\circ}$ before lipid determination could result in a release of 
fatty acid from esterified lipids producing a high level of free fatty acid on analysis; however, the plasma levels determined in the other studies with which these results are compared were also similarly stored before estimation. A major source of maternal circulating free fatty acid during labour and delivery might be expected to be liberation from adipose stores in response to catecholamines.

The proportion of arachidonic acid entering the fetal circulation has been noted to be higher than that found in the maternal circulating free fatty acid or triacylglycerol compartments in the rabbit (Elphick \& Hull, 1977a), rat (Pascaud et al. 1977), pig (Elphick et al. 1980) and cat (Elphick \& Hull, 1984) as well as in man (Filshie \& Anstey, 1978), and our results confirm these observations. Labelled studies in the rabbit, pig and cat suggest that, in these species at least, arachidonic acid is not selectively transferred from either maternal plasma free fatty acid or triacylglycerol. Thus either arachidonic acid is synthesized in the placenta from linoleic acid or appears from an alternative maternal source such as maternal plasma phospholipid. There is some evidence for placental elongation and desaturation of linoleic acid (Zimmerman et al. 1979; Noble et al. 1985), although the extent to which this occurs in vivo is unclear (Booth et al. 1981). Maternal plasma phospholipids are thought to be important for the provision of arachidonic and other long-chain polyunsaturated fatty acids to the fetus (Elphick \& Hull, 1984) in some species. The cat, for example, has a limited ability to elongate and desaturate the essential fatty acids (Rivers et al. 1975) and must, therefore, provide the fetus with arachidonic acid and other essential polyunsaturated fatty acids directly from the maternal circulation. Maternal plasma phospholipids are the most likely source since these are particularly rich in the necessary fatty acids.

Most of the studies in man quoted previously did not include measurements of arachidonic acid levels at normal delivery; the one that did (Robertson et al. 1968) reported arachidonic acid levels in maternal and umbilical plasma free fatty acids of about $1-2 \%$ and 3-4\% respectively. Similar concentrations were found in blood taken at elective Caesarean section (Hendrickse et al. 1985). The levels of arachidonic acid in the Asian women, however, were much higher, forming $11 \%$ of the maternal and $16 \%$ of the umbilical plasma free fatty acids. The high circulating levels of linoleic acid in the free fatty acid fraction of the Asian women are likely to result in increased production of arachidonic acid in maternal tissues and subsequent release into the maternal circulation. If the placenta is involved in the desaturation and elongation of linoleic acid, increased placental production of arachidonic acid could also occur. The levels of linoleic and arachidonic acids in the plasma phospholipid fraction have been found to be high in men of Indian descent living in Britain compared with those of European descent (Miller et al. 1988) and similarly higher in Caucasian vegans than in Caucasian omnivores (Sanders et al. 1978). The fatty acid composition of maternal plasma phospholipid in the Asian women was not measured and the possibility that these were also particularly rich in arachidonic acid cannot be assessed.

In conclusion, high circulating levels of linoleic and arachidonic acids were found in the plasma free fatty acid fraction of Asian women at normal delivery. Arachidonic acid appeared in the umbilical circulation at a level of $16 \%$ of the umbilical cord plasma free fatty acids and was about four times greater than that found in previous studies on mixed populations of European women. The source of this arachidonic acid could be through placental synthesis from linoleic acid or from some maternal source other than plasma free fatty acid or triacylglycerol, such as maternal circulating phospholipid. Mothers on a vegetarian diet and their offspring appear to have no problem with the supply and production of arachidonic acid. 


\section{REFERENCES}

Abraham, R. (1983). Ethnic and religious aspects of diet and nutrition in pregnancy. In Proceedings of the 10th Study Group of the Royal College of Obstetricians and Gynaecologists, pp. 23-29 [D. M. Campbell and M .D. G. Gillmer, editors]. London: Royal College of Obstetricians and Gynaecologists.

Booth, C., Elphick, M. C., Hendrickse, W. \& Hull, D. (1981). Investigation of $\left[{ }^{14} \mathrm{C}\right]$ arachidonic acid and placental transfer of linoleic and palmitic acids across the perfused human placenta. Journal of Developmental Physiology 3, 177-189.

Chen, C. H., Adam, P. A. J., Laskowski, D. E., McCann, M. L. \& Schwartz, R. (1965). The plasma free fatty acid composition and blood glucose of normal and diabetic pregnant women and of their newborns. Pediatrics 36, 843-855.

Elphick, M. C., Edson, J. L., Lawlor, J. P. \& Hull, D. (1978). Source of fetal-stored lipids during maternal starvation in rabbits. Biology of the Neonate 34, 146-149.

Elphick, M. C., Flecknell, P., Hull, D. \& McFadyen, I. R. (1980). Plasma free fatty acid umbilical venous-arterial concentration differences and placental transfer of $\left[{ }^{14} \mathrm{C}\right]$ palmitic acid in pigs. Journal of Developmental Physiology 2, 347-356.

Elphick, M. C. \& Hull, D. (1977a). The transfer of free fatty acids across the rabbit placenta. Journal of Physiology 264, 751-756.

Elphick, M. C. \& Hull, D. (1977b). Rabbit clearing-factor lipase and the transfer to the fetus of fatty acids derived from triglycerides injected into the mother. Journal of Physiology 273, 475-487.

Elphick, M. C. \& Hull, D. (1984). Transfer of fatty acid across the cat placenta. Journal of Developmental Physiology 6, 517-525.

Elphick, M. C., Hull, D. \& Broughton-Pipkin, F. (1979). The transfer of fatty acids across the sheep placenta. Journal of Developmental Physiology 1, 31-45.

Elphick, M. C., Hull, D. \& Sanders, R. (1976). Concentrations of free fatty acids in maternal and umbilical cord blood during elective Caesarean section. British Journal of Obstetrics and Gynaecology 83, 539-544.

Elphick, M. C. \& Lawlor, J. P. (1977). Quantitative recovery of free and esterified fatty acids from thin layer plates coated with silica-gel. Journal of Chromatography 130, 139-143.

Filshie, G. M. \& Anstey, M. D. (1978). The distribution of arachidonic acid in plasma and tissues of patients near term undergoing elective or emergency Caesarean section. British Journal of Obstetrics and Gynaecology 85, 119-123.

Folch, J., Lees, M. \& Sloane-Stanley, G. H. (1957). A simple method for the isolation and purification of total lipids from animal tissues. Journal of Biological Chemistry 226, 497-509.

Fosbrooke, A. S. \& Wharton, B. A. (1973). Plasma lipids in umbilical blood from infants of normal and low birthweight. Biology of the Neonate 23, 330-338.

Friedman, Z., Danon, A., Lamberth, E. L. \& Mann, W. J. (1978). Cord blood fatty acid composition in infants and their mothers in the third trimester. Pediatrics 92, 461-466.

Hendrickse, W., Stammers, J. P. \& Hull, D. (1985). The transfer of free fatty acids across the human placenta. British Journal of Obstetrics and Gynaecology 92, 945-952.

Itaya, K. \& Ui, M. (1965). Colorimetric determination of free fatty acids in biological fluids. Journal of Lipid Research 6, 16-20.

King, K. C., Adam, P. A. J., Laskowski, D. E. \& Schwartz, R. (1971). Source of fatty acids in the newborn. Pediatrics 47, 192-198.

Miller, G. J., Kotecha, S., Wilkinson, W. H., Wilkes, H., Stirling, Y., Sanders, T. A. B., Broadhurst, A., Allison, J. \& Meade, T. W. (1988). Dietary and other characteristics relevant for coronary heart disease in men of Indian, West Indian and European descent in London. Atherosclerosis 70, 63-72.

Noble, R. C., Shand, J. M. \& Christie, W. W. (1985). Synthesis of C20 and C22 polyunsaturated fatty acids by the placenta of the sheep. Biology of the Neonate 47, 333-338.

Pascaud, M., Rougier, A. \& Delhaye, N. (1977). Materno-fetal transfer of ${ }^{14} \mathrm{C}$ linoleic and arachidonic acids. Advances in Experimental Medicine and Biology 83, 145-149.

Paul, A. A. \& Southgate, D. A. T. (1978). McCance and Widdowson's The Composition of Foods, 4th ed. London: H.M.S.O.

Persson, B. \& Tunell, R. (1971). Influence of environmental temperature and acidosis on lipid mobilization in the human infant during the first 2 hours after birth. Acta Paediatrica Scandinavica 60, 385-398.

Rivers, J. P. W., Sinclair, A. J. \& Crawford, M. A. (1975). Inability of the cat to desaturate essential fatty acids. Nature 258, 171-173.

Robertson, A., Sprecher, H. \& Wilcox, J. (1968). Free fatty acid patterns of human maternal plasma, perfused placenta and umbilical cord plasma. Nature 217, 378-379.

Sabata, V. \& Wolf, H. (1970). Lipid and carbohydrate metabolism of the fetus under physiological and pathological conditions. Nutrition, pp. 193-197. Amsterdam: Excerpta Medica.

Sabata, V., Wolf, H. \& Lausmann, S. (1968). The role of free fatty acids, glycerol, ketone bodies and glucose in the energy metabolism of the mother and fetus during delivery. Biology of the Neonate 13, 7-17. 
Sanders, T. A. B., Ellis, F. R., Path, F. R. C. \& Dickerson, J. W. T. (1978). Studies of vegans: the fatty acid composition of plasma choline phosphoglycerides, erythrocytes, adipose tissue, and breast milk, and some indicators of susceptibility to ischemic heart disease in vegans and omnivore controls. American Journal of Clinical Nutrition 31, 805-813.

Sheath, J., Grimwade, J., Waldron, K., Bickley, M., Taft, P. \& Wood, C. (1972). Arteriovenous nonesterified fatty acids and glycerol differences in umbilical cord at term and their relationship to fetal metabolism. American Journal of Obstetrics and Gynecology 113, 358-362.

Stammers, J. P., Elphick, M. C. \& Hull, D. (1983). Effect of maternal diet during late pregnancy on fetal lipid stores in rabbits. Journal of Developmental Physiology 5, 395-404.

Thomas, C. R. \& Lowy, C. (1982). The interrelationships between circulating maternal esterified and nonesterified fatty acids in pregnant guinea-pigs and their relative contributions to the fetal circulation. Journal of Developmental Physiology 4, 163-173.

Tobin, J. D., Roux, J. F. \& Soeldner, J, S. (1969). Human fetal insulin responses after acute maternal glucose administration during labour. Pediatrics 44, 668-671.

Whalley, W. H., Zuspan, F. P. \& Nelson, G. H. (1966). Correlations between maternal and fetal plasma levels of glucose and free fatty acids. American Journal of Obstetrics and Gynecology 94, 419-421.

Zimmerman, T., Winkler, L., Moller, W., Schubert, H. \& Goetze, E. (1979). Synthesis of arachidonic acid in human placenta 'in vitro'. Biology of the Neonate 35, 209-212. 